

$$
\frac{8}{20}
$$
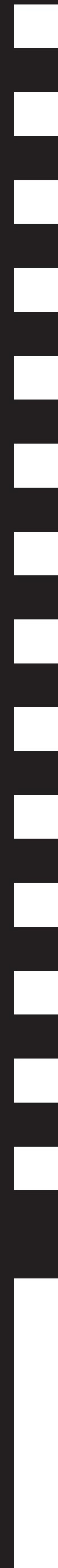
artigo ] [ ANA CLAUDIA DE OLIVEIRA ]

Professora titular da PUC-SP, coordena o Programa de Estudos Pós-Graduados em Comunicação e Semiótica e dirige o Centro de Pesquisas Sociossemióticas (CPS). Com vários livros, capitulos e artigos publicados no campo da semiótica, comunicação e arte, sua publicação mais recente é Linguagens na comunicação: desenvolvimentos de semiótica sincrética, organizada em parceria com Lucia Teixeira (Estação das Letras e Cores/CPS, 2009). E-mail: anaclaudiamei@hotmail.com

\section{Corpo, roupa, moda nas inter-relações semióticas da comunicação}

\section{Body, clothing, fashion in the interrelations of semiotics of the communication}

[resumo] Este texto objetiva fazer uma apresentação das investigações que venho desenvolvendo nas últimas duas décadas na PUC-SP, relacionando os domínios do corpo e da vestimenta com o da moda, em relação ao social. Estudos dos modos como corpo e roupa tomam parte nas práticas sociais e suas ações na construção identitária do sujeito em suas performances diárias no mundo. Para isso é empreendida uma análise dos procedimentos de dar visibilidade ao sujeito, a partir de como as articulações entre corpo, roupa e moda nos seus modos de arranjo da plástica do corpo e da plástica da moda têm uma ação na formação identitária e uma intervenção marcante nas interações sociais quer no âmbito individual, quer no coletivo. Um recorte das orientações de mestrado e doutorado realizadas e em andamento na Pós-Graduação em Comunicação e Semiótica fundamenta a abrangência das angulações de tratamento desses campos de estudo que são para nós inter-relacionados, tendo em vista os seus mecanismos de produção do sentido e significação do sujeito, do social, da cultura.

\section{palavras-chave}

$$
\begin{aligned}
& \text { corpo; roupa; moda; semiótica } \\
& \text { discursiva; pesquisa acadêmica. }
\end{aligned}
$$

[austract] inis text nas as oojective to present une investigation mave oeen aeveroping on the last two decades at PUC-SP relating the fields of the body, clothing, fashion in the configuration of the social. A study of the ways that the body and clothing are part of the social practices, and its actions on the construction of the subjects in its daily performances in the world. In order to do that it is undertaken an analysis of the procedures of providing visibility to the subject, among the body articulations, clothing and fashion on its ways of arranging the body plastic and fashion plastic in an action of identity formation and an intervention in the social interactions either in the individual action, or in the group actions. A cut in the masters and doctors researches accomplished and being done at the Postgraduate of Communication and Semiotic fundaments the coverage of the angles of treatment of this study field that are inter-related to us baring in mind that its production mechanisms of sense and meaning of the subject, social and culture.

[key words] body; clothing; fashion; discursive semiotics; academic research. 
No quarto de vestir, no armário, ao se escolher uma roupa, escolhe-se, sobretudo, valores e posições na sociedade. Com a sua plástica e os seus valores culturais, é o corpo, por algumas de suas partes, que se impõe à plástica da moda. Nesse jogo enunciativo o vestir faz ver o que em nossa sociedade é valorizado sexualmente.

Ana Claudia de Oliveira ${ }^{1}$

Pesquisas se dão por muitas partes, na academia, mas também fora dela nos processos de criação, produção e veiculação de produtos pela indústria, comércio, mercado, marketing, propaganda. Essas envolvem conceituação, fabricação, disponibilização e consumo dos produtos mercadológicos que formam o nosso entorno como uma cultura em que as mercadorias estão na centralidade das relações sócio-político-econômicas. Daremos ênfase aqui às investigações que se realizam nos cursos de pós-graduação de nosso país, em particular, os da PUC-SP, entendendo que essa instância de produção de conhecimento guarda uma independência em relação às mercadorias corpo e roupa, diferenciando, portanto, os seus modos de pesquisar e, por conseguinte, os resultados edificados.

Os interessados em realizar investigações relacionando os domínios do corpo e da vestimenta com o da moda, em relação à cultura, o mais das vezes propõem tratar os produtos, objetos e usos sociais como uma das manifestações mais férteis de estudo dos procedimentos de dar visibilidade aos processos de formação identitária, de modos e modas, assim como de definição dos vários lugares projetados para a alocação dos sujeitos que os corpos em ação habitam e ressignificam pelo rol de comportamentos e práticas sociais que estabelecem. Com suas axiologias, essas ressignificações movem o consumo e o mercado, mas também a sociabilidade, a subjetividade. Desses encontros advêm novas modas e modos de criação da aparência que intervêm na construção da identidade mutante característica da contemporaneidade.

Os aspectos envolvendo corpo e roupa e os processos de visibilidade e sociabilidade do sujeito, com uma variedade de designs da aparência, da moda, com seus regimes de presença e de pertencimento, estudados pelos regimes de interação e regimes de sentido, têm interessado e sido operacionalizados por áreas diversas do saber as quais se desenvolvem estabelecendo ou não fronteiras entre os distintos campos.

Sociologia, antropologia, história, ciências políticas, medicina, em especial, a endocrinologia e a estética, psicologia, educação física, engenharia têxtil, química, administração, marketing, gestão de negócios, design, semiótica, comunicação são alguns desses campos que podem ser considerados como as principais nucleações das pesquisas atuais. Como eles estabelecem novos modos de atuar para pensar corpo e roupa que são bastante reveladores das direções epistemológicas dos estudos das humanidades hoje, as suas direcionalidades que rompem barreiras com as ciências biológicas, exatas e tecnológicas vão merecer toda nossa atenção.

Marcadamente, quaisquer que sejam as eleições de estudo, toda investigação realizada sobre corpo e roupa é em si mesma intersemiótica, e eis um quadro de base que precisa ser mais debatido.

\section{Intersemioticidade e processos entressistemas}

Nas origens, o fato de ser mais de um sistema que nos seus usos são postos em relação para a construção do sentido impõe que, antes de qualificar as pesquisas com outras etiquetas como de interface, interdisciplinar, multidisciplinar, trans-/inter-áreas, é preciso considerar que esses tipos de pesquisas entre corpo e roupa tratam de abordagens entre dois sistemas, ou linguagens, independentes, arquitetados em seus processos de expressão para atuar intersistêmica ou 
intersemioticamente. Deriva dessa intersecção intersistêmica, em atualizações nos processos de sincretismo de linguagens, muitos dos imbricamentos epistemológicos e metodológicos de mais de um campo que vão compor as formas de abordagem. Apagar ou esquecer essa constituição especificamente sincrética desse nosso campo de estudo que tem manifestado vontade para se tornar mais um dos campos científicos é perder da mirada investigativa o fato de que operamos sobre processos e usos dos sistemas que são articulados em roupas que fazem sentido no seu atuar no corpo vestido. No dinamismo dessa cinética é que roupa e corpo edificam modos de uso construindo nas e por suas inter-relações os processos de formação do sujeito, dos grupos sociais, cujos modos de inter-relação entre grupos são um dos definidores da política do corpo na vida social e cultural.

A intersemioticidade caracteriza o estudo que articula sistemas distintos em sincretismo que são processados por um enunciador ao enunciar sentidos a outrem, o enunciatário. 0 destinador que é identificável como a indústria, a organização, a marca, o criador, o ponto de venda, todas essas instâncias assumem, na sua produção de enunciados, um modo de enunciar centrado no arranjo de expressão das escolhas intersistêmicas que se apresentam por tipos de sincretismo. Dada essa condição quase natural ou naturalizada do arranjo é que se tende a ignorar os processamentos e seus mecanismos na articulação da plástica do uso do sistema do corpo e da plástica do uso do sistema da roupa quando se trata do estudo de moda.

Postulando que todo e qualquer tratamento dessas plásticas como áreas do saber articuladas podem, em suas perspectivas várias de estudos, assumir que as teorias semióticas com seus arcabouços de fundamentos e metodologias têm possibilidade de atuar como ancilar dessas abordagens, advogamos que esse trabalho entre semiótica e outra disciplina é uma construção de grande monta que está se desenrolando com uma significativa produção de conhecimento que precisa ser mais considerada pelo seu tipo de produção de conhecimento.

Assim, gostariamos de evidenciar como temos explorado as inter-relações entre Semiótica e Comunicação nas pesquisas que orientamos na Pontifícia Universidade Católica de São Paulo, no Programa de Pós-Graduação em Comunicação e Semiótica, ao longo de quase duas décadas, com base na teoria de Algirdas Julien Greimas $^{2}$ e seus colaboradores, em especial da sociossemiótica de Eric Landowski ${ }^{3}$ e da semiótica plástica de Jean-Marie Floch².

\section{Hipóteses e testagens}

A expressão do corpo e da roupa dá-se pelo movimento, o cinetismo, uma de suas características particulares que muito tem nos interessado pela importância que desempenham em nossa cultura as várias interações entre os corpos moventes, em especial, aquelas em que a roupa vestindo o corpo (seria também o corpo vestindo a roupa) instauram as presenças do eu a si mesmo, a outros, ao mundo, às coisas que constituem tanto a(s) visibilidade(s) de um quanto a(s) dos outro(s). Por montar em sua sintaxe um sistema que está inteiramente imbricado na contemporaneidade com os regimes de subjetividade e de identidade, assumimos que essas presenças do corpo vestido são um dos modos possíveis de flagrar na imediaticidade do confronto olhos nos olhos, corpo a corpo, a(s) alteridade(s). Vivemos em contextos em que nossa interação com o outro, quer esse seja uma pessoa, um produto, uma marca, uma coisa, recebe um tratamento de estetização tamanho que, entre esses afrontamentos de corpos, o que os recobre torna visível o elevado grau de uso de cosméticos que Ihe conferem uma aparência. Essa indústria efervescente não fabrica só produtos e sua consumação, mas ela manufatura também os sujeitos. A depreensão de procedimentos que atuam na cosmetização do corpo e da face nos fascina a mostrá-los como resultados de operações subjetivas aquém e além dos processos de construção da identidade.

Como marcas dos corpos, os traços de suas corporeidades vão assumir atos pelos quais um ator se faz presente no processamento da situação comunicativa a um sujeito outro. Os modos de presença e de interatuação de um com os outros realizam-se por uma gama de tipos possíveis. Por essa via esses corpos significam justamente ao se pôr ou ser postos em relação a outro(s) corpo(s), marcando ações 
entre sujeitos em tipos de interação, de narratividade que produzem. Entre um e outro se fazem as presenças dessa alteridade com sua corporeidade, seus modos de presença ao outro que nos olham, espreitam e até nos enfrentam em busca de estabelecimento de um dos tipos de interação. Como temos postulado, tanto 0 corpo como a roupa podem ser considerados como um desses outros que têm um fazer que vai ser definido pelo modo como a sua ação é exercida sobre o outro, assim determinando os tipos de atuação que fazem o sujeito ser. Quando um desses polos assume atuar como destinador do fazer do outro sujeito, é preciso observar as condições sintáticas em que os dois interactantes vão estar colocados, posições que têm implicações na sintaxe interativa ${ }^{5}$. Os mecanismos da ação de um sobre 0 outro, ou da ação de um com o outro, definem no primeiro caso o regime de junção e no segundo o de união. Eis como a gramática narrativa de Greimas ${ }^{6}$, complementada por Landowski ${ }^{7}$, efetivamente torna-se nosso arcabouço teórico para as análises das narrativas promovidas pelo corpo e roupa no corpo vestido, assim como as da moda. Destacar as ações performativas do destinador sobre o destinatário, assim como as suas ações sancionadoras do que esse (destinador) realiza mostra as sanções sociais que permitem ou não o pertencimento social. Essas análises narrativas formam um quadro da ação de homens sobre outros homens dando destaque aos mecanismos de convencimento usados, um quadro das formas de sensibilidade vigentes, assim como um levantamento das paixões dominantes no social.

A vestimenta com sua plástica, formada em uma topologia com um volume que é o do corpo vestido, constitui-se um arranjo tridimensional de cores, formas, matérias que, nos recortes de espacialidades e temporalidades, realiza um percurso de constituição identitária ao montar uma visibilidade àquele que assim vestido a porta em suas ações e comportamentos. Como hipótese bastante vasta, testamos como a visibilidade dos corpos vestidos é produzida pela maneira com que eles estão posicionados, assumem uma postura na ocupação de um dado lugar, gesticulam, movem-se marcando por essa dinâmica corporal a intencionalidade das interações que os tornam presentes ao outro. Essa presença é uma construção semiótica que enuncia o sujeito para o mundo, mas também para si mesmo.

Cada ato de um sujeito ganha uma forma de visibilidade pelo ato do outro, o que mostra que a dinâmica estruturante da interação deixa os traçados da dinâmica de seus sentidos e orientações na produção da significação. Nos dois polos da interação, os sujeitos interatuantes são regidos por uma transitividade ou por intransitividade que determinam o tipo de interação comunicativa mantida entre enunciador e enunciatário. No caso da transitividade, a mudança nos turnos de ocupação dos polos da comunicação pode se dar por uma participação até da ordem da reciprocidade, e também em certos casos de uma ordem da reflexibilidade.

As postulações sociossemióticas de Landowski de que as interações narrativas com as suas posições sintáticas formam um regime de organização da sintaxe, e que esse regime das interações narrativas é correlato ao regime de estruturações do sentido, são tomadas por nós nas investigações da dinâmica dos regimes de presença, de visibilidade, de identidade, sustentando a nossa hipótese de que as posições enunciativas podem ser tomadas enquanto interações discursivas que igualmente enfeixam regimes que estão em correlação aos dois outros. A dinâmica dessas interações entre enunciador e enunciatário transforma o abstrato da axiologia em uma concretização que atua como a própria mídia do sentido.

Há em todas as pesquisas que foram ou estão sendo desenvolvidas considerações de maior ou menor monta sobre os tipos de arranjos da expressão. $\mathrm{Na}$ abordagem da sua plástica, são determinantes os tipos de sincretismo entre corpo 
e roupa, entendendo que as articulações entre sistemas ou linguagens são processadas de maneira que particularizam as escolhas do sujeito enunciador, singularizam o seu estilo, para produzir efeitos de sentido no destinatário. Assim a plástica da expressão é uma produção feita a partir do destinatário-alvo. Depreende-se na sua análise as marcas deixadas na etapa de produção discursiva como marcos de orientação nela fincados para guiar o enunciatário na sua construção do sentido. Assim esses dois fazeres, o do enunciador e do enunciatário, cravam nos objetos semióticos os simulacros dos que produzem o seu sentido. Tanto o enunciador que o produz na etapa de construção textual para aquele a quem o sentido é enunciado quanto esse enunciatário que, reexaminando os mecanismos de produção do sentido, o constrói outra vez. Simulacro pode então ser entendido como a construção que 0 analista realiza das figuras dos dois sujeitos integrantes dos processos enunciativos do enunciado. Essas figuras retraçam as dimensões de ordem cognitiva que são acionadas para entrar em ação racional, isto é, inteligível, de sensibilidade, isto é, do sentir estésico, no trânsito dinâmico e integrativo da inteligibilidade sensivel e da sensibilidade inteligivel que são todos tipos de operadores do fazer interpretativo. Na tarefa de significar o sentido, é que os analistas depreendem os simulacros pelas iterações dos tipos de traçados das competências plasmadas nos atos de apreender, de sentir, de raciocinar empregados no fazer ser o sentido. Esses dois simulacros são construções processadas na descrição e análise semiótica da produção da significação ${ }^{8}$.

Os arranjos da expressão sincrética são regidos por uma estética que é transladada para o sujeito vestido, qualificando-o como mostram as minhas pesquisas e as suas repercussões nas de meus orientandos ${ }^{9}$. Gostaria de destacar algumas dessas investigações que se juntam a minha caminhada de produção de um conhecimento semiótico do corpo, da roupa, da moda e mostrar por seus resultados a contribuição da teoria semiótica de Greimas para nossos estudos que se consolidam na sociossemiótica que juntos praticamos.

\section{Produção semiótica do conhecimento das inter-relações corpo, roupa, moda}

Mais além de ti, mais além de mim, pelo corpo, no corpo, mais além do corpo, queremos ver algo [...]. Não sabemos a ciência certa, o que é, excepto que é algo mais. Mais que a história, mais que o sexo, mais que a vida, mais que a morte.

Octavio Paz ${ }^{10}$

Kathia Castilho operou no seu mestrado um recorte diacrônico dos períodos históricos, correlacionando as plásticas do corpo e as da roupa na história da moda. Mostrando como essas são arranjadas por um comando enlaçado por uma estética que qualifica o sujeito vestido, o seu estudo destaca ainda a importância do conhecimento das operações normatizadas das linguagens para poder subvertê-las ${ }^{11}$. Da abordagem diacrônica, o seu recorte passou à sincronia ao se debruçar, no seu doutorado, sobre o uso de marcas do e no próprio corpo para significá-lo. Os atos de apropriação do corpo como sendo a possibilidade de expressão do sujeito foram os meandros que Castilho analisou em corpos de revistas ou de experimentações performáticas em que as operações significantes do corpo estabelecem o sentido do ser no contemporâneo ${ }^{12}$.

Claudia Garcia e Larissa Costa também foram guiadas em seus mestrados por cortes sincrônicos. Interessadas nas mudanças culturais dos usos vestimentares brasileiros, pelos tipos de uso das roupas e práticas sociais que foram articuladas na definição de regimes de identidade e de visibilidade, essas pesquisas salientaram modificações nas plásticas do corpo e da roupa correlacionadas às modificações do feminino e do masculino na atualidade. Enquanto Garcia deteve-se nas marcas de sutiãs em circulação no mercado nacional bastante globalizado para analisar os sutiãs mais usados pelas mulheres brasileiras ${ }^{13}$, Ortiz explorou as camisas que dão a ver ou apagam, ostentam ou ocultam os troncos masculinos que foram transformados do estado de parte neutralizada do corpo dos homens a uma de suas partes mais exponenciadas onde a peça vestimentar camisa é uma 
sinalização de uma dessas trajetórias ${ }^{14}$. Feminino e masculino foram estudados em um contínuo de transformações possibilitadas não só pelas inovações tecnológicas da indústria têxtil, mas também pelas configurações estéticas diferentes que passaram a delinear os troncos da mulher e os troncos do homem. Corpo e roupa que vestem a intimidade ou a esfera exterior - esferas do privado e do público que são postas em discussão - são tomados por suas articulações significantes do sujeito que se constrói na e por essas relações. Em articulação com a forma e a topologia, o cromatismo e a materialidade dos tecidos usados, há grande intervenção dos avanços tecnológicos de modelagem nas produções vestimentares atuais. A cor pode ou não dar continuidade à pele em uma extensão da cor corpórea, articulando as matérias flexíveis de modelagem das formas e texturas da roupa junto ao corpo. Mas essas ainda exercem um largo fazer valorativo do tronco e os tecidos especiais como as rendas, sedas; os adereços como cristais, brilhantes, vestem 0 corpo também com simbologias e status social. Por outro lado, é também a flexibilidade característica dos tecidos tecnológicos atuais que permite o pôr à mostra igualmente formas e volumes do tronco masculino.

Essa seleção de materiais, cores, estampas, formas com os novos padrões de modelagem foram, nessas duas investigações, examinados no ato mesmo da roupa e corpo atuando na constituição identitária. Em outras pesquisas foram examinados como as constantes reiteradas por um criador, uma marca para qualificar o seu estilo, cuja definição vai muito além da exposição da sua roupa de grife, de marca, envolvendo a concepção mercadológica que sua obra recebe dos processos de criação e processamento que envolvem a etiqueta, as coleções, os tipos de desfiles e de vitrinas que se mantêm coesamente.

Como prática social e cultural, as vitrinas recebem em sua montagem, da forração, iluminação e cenarização, um vasto investimento figurativo concretizando temas para a alocação das mercadorias, envoltas pelos desejos do consumidor que, uma vez semiotizados, nos apontam o quadro de volição, das paixões nutridas pelo sujeito e pelo social, como mostrou o doutorado de Sylvia Demetres$\mathrm{co}^{15}$. Esses arranjos sincréticos arrolados mapeiam, pelos modos de fazer sentir, o regime de sensibilidade, e pelos modos de fazer fazer, o regime de manipulação, assim como prefiguram a partir dos ingredientes do regime de programação, na sua extensão, os constituintes do regime do acidente alvo da eterna busca da sociedade de consumo em determinar as regras do "novo" que os produtores não cansam de reinventar e reformatar. 0 doutorado de João Baptista Ciacco se posiciona indagativamente em relação às ações publicitárias, examinando esse culto do novo que perdura mantendo a consumação capitalista com ares do que vem sendo chamado de "consumo democrático". "Ter o novo para ser", uma das máximas das articulações de modalidades que permite a participação do sujeito em cenas múltiplas realizadoras da sua necessidade vital e simbólica de pertencimento, torna-se assim a grife das identidades do pós-"pronto a portar", que são hoje as do "pronto a descartar".

Os mestrados de Carol Garcia sobre Ronaldo Fraga ${ }^{16}$ e de Lígia Sales sobre Lino Villaventura ${ }^{17}$ atualizam os estudos do estilo e do gosto por uma fundamentação e metodologia semiótica. No conjunto de roupas de coleções, dos seus desfiles, essas pesquisas buscam as constantes que perduram nas criações das peças. A recuperação de traços e de procedimentos de arranjos nas montagens das roupas vai ser articulada em um conjunto de reiterações que definem na sua permanência o estilo do criador e delineiam o simulacro da destinação dessa roupa. Na perspectiva daquele que se veste com roupas com essas assinaturas, evidencia-se por esse 
tipo de consumo a particular volição do sujeito que assume, com o uso da roupa nas passarelas do seu social, querer ser segundo o papel identitário projetado pelo estilista para a sua visibilidade social. 0 uso de um estilo associado a comportamentos estabelecidos transfere ao usuário o estilo do criador.

Mas, ao enfrentar essa empreitada dos traços de estilo dos criadores fui arremessada a explorar que o estilo, o gosto deixaram de ser uma exclusividade só de grandes criadores. Na sociedade de consumo em que vivemos, a construção do estilo é opção de cada um que investe na autoconstrução de sua aparência a fim dessa ser o fulcro de sua visibilidade social. 0 estilo tornou-se uma busca de todos e destacam os percursos de construção da identidade também do sujeito comum, do anônimo, que para ser no social enfrenta a prescrição de seu pertencimento a grupos sociais. Como o estilo qualifica o um e os muitos, seu estudo tem sido central para dar conta dos regimes de presença ${ }^{18}$.

0 corpo e a roupa (moda) têm sido investigados como fenômenos comunicacionais que nos permitem abordar de que maneira esses dois campos nas suas intersemiotizações são eles mesmos mídias do sujeito se expressar e se posicionar no mundo, produzindo a sua significação. Além do uso que fazem do corpo vestido no espaço os performers, atores, celebridades, interessa-nos os usos dos políticos e governantes, e mais ainda os dos sujeitos comuns que desenham a sua aparência a partir do que é posto em circulação midiática e, assim, determinam a visibilidade corpórea e a do corpo vestido. Os modos de se fazer presente nos espaços de sociabilidade das urbes seguem padrões desses grandes receituários, mas também apontam as formas de transgressões, de recriações. Dessa maneira, tratamos não só o corpo e a roupa nas mídias como cinema, revista, jornal, internet, publicidade, nos programas de entrevista, auditório, nas criações de grandes estilistas, na caracterização de personalidades políticas e do grand monde, que o rótulo celebridade unifica como visibilidade exponencial das formas de usos e de consumo.

Contudo, também há um interesse crescente em investigar como o corpo vestido interage e sua corporeidade processa o sentido das apreensões significantes dos seus sentidos que são destacadas em várias pesquisas. Nas de Cíntia SanMartin Fernandes é a semiotização das ações, aparências e dos comportamentos na Galeria do Rock, em São Paulo, que vão explorar a visibilidade dos grupos que aí circulam. Essa localidade do centro antigo incorpora o seu passado no presente e, sob os auspícios de sua arquitetura delineando a sua espacialização particular, são aí atualizados modos de sociabilidade, visibilidade particulares reveladores de uma das formas de vida na cidade ${ }^{19}$. As interligações entre a parte e o todo, no presente caso, a parte pelo todo, mostram um dos modos da metodologia semiótica extrair as suas generalizações.

Na base dos estudos doutorais de Regilene Sorzi, essas interligações vão evidenciar explicitando que na teoria semiótica do discurso não realizamos estudos de caso, mas cada objeto de estudo testa os conceitos como instrumentais de descrição e análise que permitem ascender aos procedimentos de construção do sentido. Os fragmentos do corpo atualizados em performances artísticas da videoarte vão ser tomados como um processo de construção em que essa parte vale pelo todo. Essa visibilidade metonímica constrói um modo de ver a significação do corpo e do sujeito assumida pelo social que se quer ora explicitar, ora criticar, ora subverter e fazer outras propostas de uso.

Estudado como reiterações de traços, de procedimentos, usos que mostram a continuidade na descontinuidade, a permanência de um arranjo plástico, de constantes figurativas, temáticas enunciativas possibilitam a determinação de quem os processa e para quem são processados. Os simulacros do destinador e do destinatário é uma das construções-alvo da investigação semiótica. Nesse mesmo âmbito das caracterizações dos estilos dos criadores de moda, de usuários, a pesquisa de pós-doutoramento de Anamélia Bueno Buoro sobre fotografia de moda desenvolveu uma de suas partes com uma equipe de jovens mestrandas do Senac que estudou o traçado identitário da top model brasileira Gisele Bündchen ${ }^{20}$. A singularidade dos seus passos, o seu ritmo nas passarelas dos desfiles de moda, a marcação do balanço de seu jogo de corpo e de sua postura em cena operam como as qualidades que definem o seu estilo. 
Em uma tomada mais generalizante, passamos a indagar a que servem os desfiles de moda? Quais são os seus ingredientes? Em um espaço escolhido, como se arquiteta a construção dos lugares de prestígio projetados para uma determinada ocupação pelas várias personalidades convidadas? Dos postos dos jornalistas e fotógrafos aos dos seletos que são compradores e outros usuários e convidados especiais, como se articulam as relações entre essas espacialidades com atorialidades específicas e a estruturação da cobertura midiática? Sendo a grande vedete dos desfiles pelos seus registros, a câmera fotográfica nos seus clicks realiza a cobertura segundo a perspectiva de uma angulação que quer ser tomada como enfoque global. Este intervém nas crônicas jornalísticas de moda, juntamente com os dos sonoplastas, dos iluminadores que fazem os destinatários visualizar mais as partes evidenciadas para serem vistas. 0 desfile é uma criação de ambientes de uma experiência tramada para ser vivida no "aí" e "agora" por um público seleto que é captado nas suas várias formas de presença para ser notícia como o são as milhares de tomadas da passarela. Como cada uma das celebridades envolvidas nas passarelas, duas vezes ao ano, anuncia a cada desfile uma nova estação que alavanca a economia nos seus modos de produção e consumo? Mostrando os desfiles, a moda torna presente na passarela o futuro dos usos vestimentares. A distância entre as temporalidades converte-se no tempo em que a alta-costura, o prêt-à-porter são traduzidos em cadeias de roupas mais acessíveis aos demais segmentos sociais, formando uma escala de transcriações que instigam os estudos das traduções e das intertextualidades que são bastante mais complexos do que os rótulos, do que as cópias e o pastiche. Como essas criações exalam o "ar do tempo" de grandes maisons, de grandes estilistas àqueles que vivem dos simulacros de aparência? Como o público dos desfiles propaga aos demais usuários as novas a ponto de essas atingirem as pessoas comuns das ruas? As criações de imagens são criações conceituais das maisons de couture, dos criadores, das top models, e vão movimentar o prêt-à-porter e as confecções que vestem os corpos dos usuários que desfilam nas passarelas urbanas.

Esse encadeamento do virtual ao realizado e manifesto nucleia o mestrado de Jô Souza, mas o campo é vasto e as variadas declinações dos desfiles do elitismo à democratização do luxo estão à espera de sensibilizar outros olhares originando novas investigações. Jô Souza problematiza os próprios desfiles de moda, destacando como cada criador na passarela usa as suas marcas singulares, seu estilo para ser lembrado e marcar seu modo de presença. Grandes aparatos são usados na encenação desses corpos modelos a ser seguidos e, evidenciando que as passarelas são as próprias ruas, estão os seus trabalhos práticos na avenida Paulista, passarela de sua organização de desfile na pauliceia ${ }^{21}$.

Na fotografia, ensaios fotográficos, pintura de celebridades, crônica jornalística, documentário, as figuratividades com os traços caracterizadores dos seus mundos, assim como os de sua manifestação em linguagens, os processos da sintaxe narrativa nas interações entre sujeito e objeto, assim como os processamentos das interações discursivas entre o fotografado/pintado/etc. pelo destinador e aqueles que o olham, o destinatário, mostram o estilo dos modos de fazer ser 0 retratado/pintado ou autorretratado. Examinando o corpo, a roupa e os enlaçamentos desses em uma prática social, Daniela Bracchi tomou como desafio em seu mestrado a obra fotográfica de LaChapelle, caracterizando a construção da intertextualidade e das interações discursivas entre enunciador e enunciatário como a determinação de seu estilo. Enquanto esse criador mostra no campo da fotografia a edificação de sua expressão, alicerçada nos caminhos da pintura com a história 
de técnicas e procedimentos da visibilidade pictórica distinta da visibilidade fotográfica, ele faz ver e sentir as possibilidades de realização da mídia fotografia e se individualiza na prática fotográfica ${ }^{22}$. Em um enfrentamento que faz do estilo dos pintores a construção do si identitário do pintor, o doutorado de Lauer Alves Nunes dos Santos investigou como os pintores do século XX empreenderam uma reflexão sobre a pintura e o autorretrato de épocas distintas, usando-os como meios de expressão, de enunciação pelas marcas distintivas dos arranjos plásticos empregadas no autoapresentar-se, autofigurativizando-se de modos diferenciados a sua relação com o seu ofício: a pintura. Conceituando o fazer, o artista, a arte e seus procedimentos, o corpo do artista e/ou o corpo da pintura, a tese de Lauer entreteceu os fios de concepções pictóricas da pintura que postulam os seus próprios desdobramentos na pintura da contemporaneidade. A tradição iniciada nos registros de Plinio, o Velho, retomada emblematicamente por Van Dyck e Velázquez, o posicionamento do artista na sociedade é posto em discussão. Nos modos de sua autoapresentação, o sujeito, artista em cena, mostra-se com o seu corpo, alma e mente, conceituando-se, assim como ao seu fazer pictórico ${ }^{23}$. Maria Auxiliadora Corassa explorou, no seu doutorado, as poses dos corpos de casais retratados na pintura do século XIX e primeira metade do século XX. Os modos como esses corpos estavam postos um em relação ao outro, os modos de se vestir, de se posicionar em relação a um circundando em que o casal interage para ser visto, foram tomados como determinantes de modos de estar juntos para interpretar as concepções de casal, de relacionamento em suas transformações na sociedade brasileira ${ }^{24}$.

Outros caminhos derivativos para pensar os fundamentos e processamentos da enunciação visual estão esboçados nos estudos da sociossemiótica, mas solicitando ainda maiores detalhamentos das marcas de actorialidade do sujeito da enunciação. Esse eu-tu complexo do ator são corpos em interações pelas quais se desenrolam, na instância discursiva, no articular entre movimento e estaticidade dos atores no seu turno de ação, nas posturas, gesticulações, distâncias que caracterizam o como esse corpo, ao agir, operacionaliza os modos de sentir do parceiro, que mostram ao corpo próprio do outro com quem interage os modos de sentir, que podem ser partilhados em caso de um enunciatário com quem se estabelece uma parceria colaborativa, ou que são ensinados, requerendo um aprendizado do enunciatário. Essas formas de sentir e os ensinamentos do sentir dão-se na duração do ato de produção do sentido, que definem os diferentes tipos de construção colaborativas ou não do sentido ${ }^{25}$.

Os resultados dessas pesquisas nos fazem apostar que o estilo não é uma exclusividade de grandes costureiros, estilistas, criadores de moda, de pintura, de fotografia, de marcas, de instituições entre as quais a dos meios de comunicação de massa que assumem uma pluralidade de extensões, mas também dos enunciatários projetados nas produções desses enunciadores. Uma particularidade do agir de cada um desses sujeitos comuns dá-se por meio de sua autoconstrução, quer nos modos de se vestir, quer nos modos de manifestar-se por sua corporeidade ao se dar a ver no social com seus modos de presença, quer por suas formas de levar a vida, de consumir, de suas formas de gosto, de prazer ${ }^{26}$. Quem, artista ou homem comum, não está envolvido, e mesmo comprometido, com o encontro de seu lugar e de sua presença no mundo? Na construção subjetiva, o estilo e o gosto definem todo e qualquer sujeito, sendo imperativo para um ser se tornar sujeito, um percurso de construção de um estilo próprio, mostrando seu gosto ou um percurso de adoção do estilo e do gosto do(s) outro(s).

Elaborada ao longo dos anos desses estudos sobre o corpo e a roupa, a tipologia do corpo vestido que propusemos tem sido testada em corpos de distintas épocas para além da contemporaneidade que tratamos ${ }^{27}$. Os corpos da Antiguidade e seu padrão de beleza clássica perduram como atestam Apolo e a Vênus de Milo ${ }^{28}$, entre tantos exemplos que atravessam vários tempos e espaços. Suas túnicas deixavam entrever mais ou menos sugestivamente o corpo figurativizado que, na sua movimentação, evidenciavam aqui, lá, alhures, a entrevisão do corpo vestido. Transladando uma espacialidade e temporalidade para outros atores, o esplendor de Fortuny está no plissado de suas túnicas que reproduz expansivamente o jogo de retas e curvas do corpo em sua movimentação que projeta o corpo vestido no 
mundo. Esse corpo da Antiguidade, tornado um corpo clássico, é ainda um corpo alvo do desejo de o ter ainda hoje. Recriado em tantas modas, o corpo solto, mas com o busto ajustado marcando essa libertação das outras partes, foi reatualizado na moda Império e, de novo, é moda com o seu talhe na altura do busto, na atualidade. Deixando de considerar a unidade das partes pelo todo corpóreo, a ênfase de colo e seio dá destaque ao pescoço e à cabeça. A parte atratora do olhar do outro centrada nos seios, uma das marcas mais distintivas do feminino no Ocidente, leva o olhar do outro com quem se interage só depois de ter aí pousado ser elevado pelo colo, pescoço nu até a cabeça ${ }^{29}$. Na condução das direções dos olhares de quem olha, quer seja uma mulher vestida, quer seja um homem, estão plasmados os veios das concepções da mulher, do homem, do social. Nesse ir e vir do que é moda nos períodos históricos é que o corpo da moda organiza-se em uma perpétua recriação de corpos já existentes que mantêm o programa narrativo característico de todas as modas: o de exibir o corpo ditado pela moda, um ditame que obriga 0 sujeito a seguir seus passos para ser. Em cada uma de suas reaparições, outras estratégias e axiologias são postas em ação e assim as vogas, como ondas, vão e vêm.

Assim, há nas pesquisas ângulos de articulação entre as estéticas da roupa e as estéticas do corpo, com as éticas de cada periodização. Em uma abundância de interesse pelo contemporâneo, são muitos os que refletem sobre o corpo em suas várias manifestações, desde a dança, o teatro, a performance, até as conversas face a face, sobre corpo e roupa em suas articulações plásticas e figurativas de um tipo de um segmento social, de um estilo, assim como sobre ações do corpo e da roupa em vários contextos como constituintes da subjetividade dos sujeitos, de seus modos de visibilidade que produzem modos de ser e estar de onde se estampam políticas do corpo, da roupa nas várias manifestações subjetais.

Nesse âmbito, arrolam-se as investigações de Célia Dias sobre as manifestações das emoções, em especial do efeito de sentido de ciúmes, a partir do corpo vestido e de seu cinetismo gesticulante nas interações corpo a corpo que engendram os seus modos de fazer o outro sentir emoções, estados d'alma e de ânimo. A escolha de Capitu nas linhas do livro de Machado de Assis e no audiovisual da minissérie recém-veiculada pela Rede Globo de Televisão mostra a atualidade do ciúme. Toda uma linha de investigação é orientada sobre os corpos masculinos e femininos nas mídias audiovisuais e verbo-visuais que muito nos faz debruçar sobre a caracterização contemporânea de simulacros da aparência ${ }^{30}$. Distintamente do conceituado por Baudrillard como simulacro, já pontuamos que, na teoria semiótica, simulacro não é definido como o falso, mas como sinônimo de uma construção. Com as figuras de mundo traduzidas pelos arranjos do plano da expressão, os actantes da enunciação deixam-se apreender um ao outro, assim nos objetos vários são mostradas as competências modais de ordem cognitiva do inteligivel e do sensível que são necessárias na criação do seu parecer e da sua aparência que nós, os outros, edificamos a partir de marcas constantes que modelam o seu agir na situação comunicativa. Representativas das competências cognitivas dos atores da enunciação, essas competências nos trazem as respectivas instalações tanto do enunciador quanto do enunciatário com seus mecanismos de raciocinar, de sentir o sentido sensivelmente, como exploramos antes na definição das interações discursivas.

Nas manifestações das mídias impressas, sua visualidade gráfica expressa por meio das cores, figuras geométricas, marcação de tempo e o lugar que ocupam na topologia especial, vão lhe dar grande ênfase, fazendo com que as construções de figuratividade sejam regidas pela intencionalidade de fazê-la funcionar como uma 
orientação que age sobre os corpos os afetando. Em conjunção ou disjunção com esses indicadores, sujeitos traçam programas narrativos de base, modalizados pela estratégia de destinadores que os persuadem a buscar esse objeto de valor no cotidiano de suas práticas de vida. Com a glocalização acelerada convivendo com a globalização, esse destinatário tem sido aproximado de índices e taxas relativas às doenças e mortes, à vida afetiva e sentimental, aos conceitos de saúde e de beleza do corpo, aos hábitos e gostos, que são mostrados por uma figuratividade quantitativa a qual exerce um argumento de credibilidade no destinatário. 0 mestrado de Adelina Bracco tratou de como essas construções de figuratividades dos índices produzem efeitos somático-patêmicos e de como esses tipos de afetação sensivel ocorrem, pois em nossa sociedade domina uma tendência à fidúcia do número e não à desconfiança desse modo de dizer ${ }^{31}$. As rádios, a internet, a televisão também mostram que essa figuratividade impressiona e faz calar.

Nos mapeamentos em publicidades, revistas, telenovelas e demais programas televisuais, em filmes, os modelos de homem e de mulher, de masculino e feminino figuram modos de aparência que nos permitem por suas reiterações depreender os seus simulacros. Nós extraímos das aparências postas em circulação não uma verdade, mas dizeres verdadeiros que as mídias nos expõem pelas figuratividades reiterativas do masculino, do feminino, do social e do reoperar nos modos de enunciação as posições dos atores nos seus modos de interação $0^{32}$.

Nessa perspectiva, os usos de corpos nas mídias impressas, focalizando revistas semanais, destinadas a um público de interesse geral, foram estudados no mestrado de Simone Bueno, a partir das revistas Veja, Época e ISTOÉ, abordando uma exploração de como o encarnar essa modelação social de prescrições do modo de ser é regida por uma ética e uma estética na contemporaneidade, erigida no eixo semântico da beleza e da saúde, validada tanto nos extremos pelas dores sociais da anorexia ou da obesidade mórbida ${ }^{33}$. Rosane Schmitz Fernandes se debruça em seu mestrado sobre a aparência da mulher dos anos 1950 na revista Cruzeiro, nos desenhos de Alceu Penna; Letícia Mesquita analisou como a revista Nova, publicada pela Editora Abril desde 1973, constrói a masculinidade nas seções Reportagens e 0 ponto de vista. Esse homem tem o perfil sonhado pelas leitoras da revista e a sua virilidade é tomada como um novo atributo valorativo do homem brasileiro que tem sensibilidade. Esse parceiro desejado é projetado nas páginas da revista para viver com a leitora encontros que já se realizam com esse estar juntos no mundo de $\mathrm{Nova}^{34}$. Examinando o mesmo semanário, Maria Paula Piotto Guimarães definiu as aparências da mulher nos trinta anos da revista Nova, no seu mestrado. Suas conclusões a levaram a regimes de construção da mulher centrados em suas tomadas de posição referente à sua sexualidade. A leitora de Nova instalada escancara os seus desejos, e seu percurso é obsessivo na busca de estar com um homem ${ }^{35}$. Atualmente, no seu doutorado, Paula Guimarães se dedica às aparências do homem contemporâneo na mídia impressa especializada, em um projeto de correlacioná-lo ao tratamento da mulher e do social articulado pelas mídias impressas. Nessa mesma esteira, Caroline Suellen Cardoso, em seu mestrado, reconhece que essa cristalização de valores segmentados por grupos de mulheres tem nas celebridades a encarnação corpórea ideal para um atuar prescritivo e pedagógico que ensina a ser e relacionar-se socialmente com os sujeitos do mundo. Nos percursos narrativos e enunciativos que depreende, estão as modelações sociais de nossa sociedade brasileira a partir de prescrições identitárias dos sujeitos no social.

Outros segmentos da sociedade, como os imigrantes, foram explorados pelo doutorado de Ana Silvia Médola na telenovela da Rede Globo, Terra Nostra, mostrando as marcas de italianidade cravadas na cultura brasileira em sua gastronomia, nos falares melodiosos, nos costumes, assim como nas narrativas dos afetos ${ }^{36}$.

Desenvolvendo a roupa e o corpo no eixo da construção da visibilidade e da identidade, o figurino em minisséries, novelas, filmes, telejornais, entre outros, são mostrados em dois mestrados, os de Mirella Luiggi e o de Cristina Freire, que se debruçam sobre o papel que a roupa exerce no construir o corpo dos actantes, seu modo de agir e comportar-se que qualificam a sua presença em cena. As interdefinições de corpo e roupa montam um dos constructos mais significantes da identidade do sujeito. 
Problemáticas da tradução intersemiótica, da intertextualidade, da interdiscursividade, do simulacro, são atualizadas em todas essas minhas orientações para compreender as escolhas do enunciador, para mostrar, por suas interligações com a história da arte, da moda, literatura, cinema e das próprias mídias, assim como interligações com outros sistemas, como se dá a produção semiótica do sentido.

Uma pesquisa sobre os astros e celebridades é desenvolvida tomando-os como estruturas modelares que ensinam as suas fórmulas de sucesso de projeção social do individual. A visibilidade dos designs de aparências é posta em circulação nas mídias para que os outros possam ser como esses que galgaram a fama, e os seus modos de presença e de viver a vida, ao exemplificar modos de presença, atuam como simulacros para modelar a sociedade com a mesma subjetividade. De comum, esses modelos são simulacros de sujeitos a imitar, assim como os usos de sutiãs de marcas estudados por Garcia expunham formas de visibilidade dos seios que articulavam uma visibilidade definidora da mulher brasileira, e os usos de camisas selecionadas por Costa evidenciavam o tronco de uma nova masculinidade do homem brasileiro. 0 mestrado de Carlos Augusto Alfeld Rodrigues analisou os programas Superbonita e Contemporâneo, programas televisuais temáticos, com uma determinação do destinador GNT que faz parte da rede de canais Globosat, para atuar na construção do gosto da audiência feminina e masculina. Reagindo aos estímulos e impulsões dos astros e estrelas das novelas da Globo, agindo como homens e mulheres comuns como o público é inteiramente levado a se identificar, esses comportamentos vão agir como uma prescrição de ser bonita, ser de hoje que é sentida agindo nos corpos e nas ações do destinatário, que é convencido desde que se põe em relação de aprender com que sabe e pode. Esse fazer sentir é para animar a volição do programado que recebe investimentos eufóricos de uma semantização que torna as prescrições e seus resultados bastante sedutores ${ }^{37}$. No mesmo flanco, analisando um quadro do dominical Fantástico da Rede Globo, o doutorado de Christiane Maria da Bôa Viagem Oliveira elucida os procedimentos de manipulação que têm sido relacionados com os de sensibilidade, visando por esse seu arranjo particular fazer a família brasileira, em especial, a mulher, a continuar executando os mesmos fazeres narrativos que sempre desempenhou. 0 retrato da mulher é feito como um sujeito criativo, inventivo, bem-humorado e que faz os outros rirem de si como ela própria, no seu continuar solucionando tudo, permanecendo como a fada do lar. Essa mulher é uma multidão que assume manter o papel intocável da mulher na sociedade brasileira. Assim, a mulher desenhada pelo caso contado em Retrato Falado, caso esse cômico que lhe dá seus minutos de renome, faz rir a todos os telespectadores com as suas peripécias, a fim de continuar mantendo o seu dia a dia. Ao ser construída assim, essa mulher constrói também o homem brasileiro e a nossa sociedade, produzindo identificações e um contrato de adesão à visão de mundo de saber rir de si mesmo ${ }^{38}$. Outros quadros mais abundam, nos levando aos simulacros e às estruturações processadas para as suas cristalizações. Simulacros são pois prescrições para outros sujeitos e suas orientações de modos de ser são depreendidas por aqueles que os observam mais por suas gestualidades, comportamentos, posturas, expressividade, modo de olhar, andar, movimentar-se no agir do sujeito vestido, que ensina aos demais como portar tais simulacros para ser, enfim, segundo esses simulacros no social.

Um conjunto de estereótipos e normatividades são expressos então sob um invólucro de naturalidade nos contextos em que também nós existimos e que esses corpos gravitam em nossa órbita ensinando seus modos de ser e assumir aparências socialmente aceitas que prometem pertencimentos a grupos sociais almejados. 
Essas investigações apontam um mapeamento dos simulacros, quer dos destinadores, quer dos destinatários, e ainda oferecem o que eles nos fazem ser na sociedade contemporânea, o que não é de menor relevo para as investigações do sujeito. As interdefinições entre os simulacros mostram que há neles uma estrutura intersubjetiva que nos permite reoperar os sujeitos, e daí a importância dessa angulação do enfoque. A interdefinição mostra a sua rentabilidade e o seu potencial criador para uma semiotização das aparências. As testagens indicam o funcionamento do modelo semiótico e asseguram sua eficácia e seu rigor científico nas análises dos simulacros midiáticos. Por meios não tautológicos, mas advindos da interdefinição dos conceitos e usos contemporâneos, há um avanço no estudo semiótico das modalidades de aparência. Em relação à realização, há uma virtualização pressuposta e, opondo-se à atualização, há uma potencialização também pressuposta. 0 que é semiotizável é o manifestado, um parecer que é atualização do ser, uma aparência com a qual o sujeito se mostra no social, e nosso projeto é estudar as aparências que o sujeito assume na construção de sua visibilidade. Adotamos um tratamento dos modos como o sujeito constrói a sua aparência, assinalando seus mecanismos de estruturação e funcionamento que significam o sujeito.

Para além dos simulacros de pertencimento social, são ainda oferecidos aos integrantes de nossa sociedade formas de prazer e de aprazer-se nos atos de se vestir. 0 contato corpo e roupa é um amplificador de sensações das quais se podem sorver qualidades singulares de bem ou mal-estar, conforto ou incômodo, por exemplo, advindos da roupa que se veste. 0 próprio gosto de si mesmo e do outro é que faz o sujeito provar um rol de experiências sensíveis instauradas pelas inter-relações entre seu corpo e a roupa, sua aparência e performance, sua aparência e visibilidade, sociabilidade que o sujeito experimenta como ordem de vivências dos seus sentidos e da sua razão com passagens abertas do inteligível ao sensivel. Essas estesias e suas sinestesias ou multiestesias e as interligações com a razão são um campo aberto de estudo das experiências do vestir o corpo para ser, e essa trajetória, que pode ser eufórica ou disfórica, tem o seu ápice eufórico no gosto do gosto de ser um. Mas também muitos, tantos quantos se consegue parecer ser ou, no reverso disfórico, nenhum.

Essa minha reflexão é um recorte que revisa as investigações que tenho acompanhado como orientadora participante que compartilha com o orientando um percurso de construção da investigação e do investigador. A pesquisa do outro tem tido para a minha própria sentidos de expansões e multiplicações de mim mesma... Reside aí o meu cultivo desse gosto da pesquisa do outro, da pesquisa coletiva que me faz mais sentir a que me é própria. 


\section{NOTAS}

[1] OLIVEIRA, A. C. de. Espaços-tempos (pós-) modernos ou na moda, os modos. In: GINSBURG, J.; BARBOSA, A. M. (Org.). 0 pós-modernismo. São Paulo: Perspectiva, 2005, p. 513.

${ }^{[2]}$ GREIMAS, A. J. Sobre o sentido: ensaios semióticos. Petrópolis: Vozes, 1975; . Du sens II: essais sémiotiques. Paris: Seuil, 1983; (Org.). Semiótica plástica. São Paulo: Hackers/CPS, 2004, p. 75-96; Hackers, 2002

${ }^{[3]}$ LANDOWSKI, E. Moda, política e mudança. In: _. Presenças do outro: ensaios de sociossemiótica II. São Paulo: Perspectiva, 2002, p. 91-124;_. A sociedade refletida: ensaios de sociossemiótica I. São Paulo/Campinas: Educ/Pontes, 1992.

${ }^{[4]} \mathrm{FLOCH}$, J. M. Sémiotique, marketing et communication: sous les signes, les strategies. Paris: PUF, 1990; Identités visuelles. Paris: PUF, 1995.

${ }^{[5]}$ OLIVEIRA, A. C. de. Nas interações corpo e moda, os simulacros. In: COLÓOUIO DO CENTRO DE PESOUISAS SOCIOSSEMIÓTICAS, XIII, 2007. Anais do XIII Colóquio do CPS. São Paulo: CPS, 2007. CD-ROM;

Do reino do luxo à república do gosto: o gosto das interações sociais. dObra[s], São Paulo, Estação das Letras e Cores, v. 1, n 1, p. 32-35, out. 2007.

${ }^{[6]}$ GREIMAS, A. J.; COURTĖS, J. Dicionário de semiótica. São Paulo: Cultrix, 1984. Consultar as entradas dos verbetes "programa narrativo" e "programação", p. 352-356; e "manipulação", p. 269-272.

[7] LANDOWSKI, E. Les interations riquées. Limoges: Pulim, 2005 2004.

Passions sans nom. Paris: PUF,

${ }^{[8]}$ Em razão da relevância desse conceito na teoria semiótica e na minha pesquisa indico para outras consultas o verbete "simulacro" assinado por Landowski. In: GREIMAS, A. J.; COURTĖS, J. Sémiotique: dictionnaire raisonné de la teorie du language. Paris: Hachette, 1986. Tome 2, p. 206.

[9] OLIVEIRA, A. C. de. Enunciação e estesia na expressão sincrética. In: _. . TEIXEIRA, L. (Org.). Linguagens na comunicação: desenvolvimentos de semiótica sincrética. São Paulo: Estação das Letras e Cores/CPS, 2009, p. 79-140; __.. As interações discursivas na comunicação: estesia e experiência". In: IBERCOM, XI, 2009, Funchal. Anais do XI IBERCOM. Funchal: Universidade da Madeira, 2009. CD-ROM; . Interações discursivas como regimes de experiência. In: CONGRESSO LUSOCOM, 8 , 2009, Lisboa. Anais do $8^{\circ}$ Congresso LUSOCOM. Lisboa: Universidade Lusófona, 2009. CD-ROM.

${ }^{[10]}$ PAZ, O. Los signos en rotación y otros ensayos. Madri: Alianza Editorial, 1971.

${ }^{[11]}$ CUNHA, K. C. Configurações de uma plástica: do corpo à moda. São Paulo, 1998. Dissertação (Mestrado em Comunicação e Semiótica). Programa de Estudos Pós-Graduados em Comunicação e Semiótica, Pontificia Universidade Católica de São Paulo.

${ }^{[12]}$ CUNHA, K. C. Do corpo presente à ausência do corpo: moda e marketing. São Paulo, 2004. Tese (Doutorado em Comunicação e Semiótica). Programa de Estudos Pós-Graduados em Comunicação e Semiótica, Pontifícia Universidade Católica de São Paulo.

${ }^{[13]}$ GARCIA, C. R. Entre o estésico e o cosmético: estudo das lingeries brasileiras. São Paulo, 2005. Dissertação (Mestrado em Comunicação e Semiótica). Programa de Estudos Pós-Graduados em Comunicação e Semiótica, Pontifícia Universidade Católica de São Paulo.

${ }^{[14]}$ COSTA, L. O. T. Comunicação e valores do masculino: a construção da identidade na relação entre o corpo e moda. São Paulo, 2007. Dissertação (Mestrado em Comunicação e Semiótica). Programa de Estudos Pós-Graduados em Comunicação e Semiótica, Pontifícia Universidade Católica de São Paulo.

${ }^{[15]}$ DEMETRESCO, S. Vitrina: construção de encenações. São Paulo, 1999. Tese (Doutorado em Comunicação e Semiótica). Programa de Estudos Pós-Graduados em Comunicação e Semiótica, Pontifícia Universidade Católica de São Paulo.

[16] GERALDI, M. C. G. Moda e identidade na contemporaneidade brasileira: uma análise das coleções de Ronaldo Fraga. São Paulo, 2001. Dissertação (Mestrado em Comunicação e Semiótica). Programa de Estudos Pós-Graduados em Comunicação e Semiótica, Pontificia Universidade Católica de São Paulo.

[17] SALES, L. de O. A identidade da marca Lino Villaventura na moda brasileira. São Paulo, 2004. Dissertação (Mestrado em Comunicação e Semiótica). Programa de Estudos Pós-Graduados em Comunicação e Semiótica, Pontifícia Universidade Católica de São Paulo.

${ }^{[18]}$ OLIVEIRA, A. C. de. Espaços-tempos (pós-) modernos ou na moda, os modos. In: GINSBURG, J.; BARBOSA, A. M. (Org.). 0 pós-modernismo. São Paulo: Perspectiva, 2005, p. 473-532.

${ }^{[19]}$ FERNANDES, C. S. Os simulacros da cidade: a galeria do rock como um "alto lugar". In: COLÓQUIO DO CENTRO DE PESQUISAS SOCIOSSEMIÓTICAS, XIII, 2007. Anais do XIII Colóquio do CPS. São Paulo: CPS, 2007. CD-ROM.

${ }^{[20]}$ BUORO, A. B. et. al. Giseles: a construção de Gisele Bündchen. In: COLÓOUIO DO CENTRO DE PESOUISAS SOCIOSSEMIÓTICAS, XIV, 2008. Anais do XIV Colóquio do CPS. São Paulo: CPS, 2008. CD-ROM. 


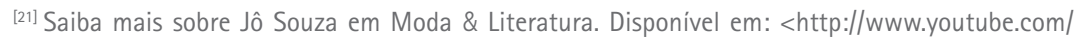
watch? $v=$ PmZHIr7008c $>$.

${ }^{[22]}$ BRACCHI, D. N. A fotografia em David LaChapelle. São Paulo, 2009. Dissertação (Mestrado em Comunicação e Semiótica). Programa de Estudos Pós-Graduados em Comunicação e Semiótica, Pontifícia Universidade Católica de São Paulo.

[23] SANTOS, L. A. N. dos. Regimes de visibilidade e construção de simulacros: o auto-retrato contemporâneo. São Paulo, 2003. Tese (Doutorado em Comunicação e Semiótica). Programa de Estudos Pós-Graduados em Comunicação e Semiótica, Pontifícia Universidade Católica de São Paulo.

${ }^{\text {[24] }}$ CORASSA, M. A. de C. Cenas de casais na pintura brasileira: construção visual de papéis sociais. São Paulo, 2004. Tese (Doutorado em Comunicação e Semiótica). Programa de Estudos Pós-Graduados em Comunicação e Semiótica, Pontifícia Universidade Católica de São Paulo.

${ }^{[25]}$ OLIVEIRA, A. C. de. Enunciação, regimes de interação discursivas e contratos. No prelo.

${ }^{[26]}$ LANDOWSKI, E.; FIORIN, J. L. (Org.). 0 gosto da gente, o gosto das coisas: por uma sociossemiótica do gosto. São Paulo: Educ, 1997. OLIVEIRA, A. C. de. 0 sabor de Sabor Pão de Açúcar. In: LEMOS, A. L. M. et al. (Org.). Mídia. Br. Porto Alegre: Sulina, 2004, p. 145-178.

[27] OLIVEIRA, A. C. de. Por uma semiótica da moda. In: CASTILHO, K.; GALVÃO, D. (Org.). A moda do corpo o corpo da moda. São Paulo: Esfera, 2002; _. Moda e identidade brasileira. In: COLÓQUIO NACIONAL DE MODA, $1^{\circ}, 2005$, Ribeirão Preto. Anais do $1^{\circ}$ Colóquio Nacional de Moda. Ribeirão Preto: Centro Universitário Moura Lacerda, 2005. CD-ROM; . Corpo e roupa nas transmutacões da aparência. In: ENCONTRO ANUAL DA ASSOCIAÇÃO NACIONAL DOS PROGRAMAS DE PÓS-GRADÚAÇÃO EM COMUNICAÇÃO, XVI, 2007, Curitiba. Anais da XVI COMPÓS. Curitiba: COMPÓS, 2007. CD-ROM;

Visualidade processual da aparência. In: OLIVEIRA, A. C de.; CASTILHO, K. Corpo e moda: por uma compreensão do contemporâneo. São Paulo: Estação das Letras e Cores, 2008, p. 93-104.

[28] OLIVEIRA, A. C. de. Aphrodite de Milo na transversalidade do sentido de mulher, beleza e moda. In: ENCONTRO ANUAL DA ASSOCIAÇÃO NACIONAL DOS PROGRAMAS DE PÓS-GRADUAÇÃO EM COMUNICAÇÃO, XIV, 2005, Niterói. Anais da XIV COMPÓS. Niterói: COMPÓS, 2005. CD-ROM.

[29] OLIVEIRA, A. C. de.; CASTILHO, K. Moda e classicismo. In: GUINSBURG, J. 0 classicismo. São Paulo: Perspectiva, 1998, p. 317-346.

[30] OLIVEIRA, A. C. de. Nas interacões corpo e moda, os simulacros. In: COLÓOUIO DO CENTRO DE PESOUISAS SOCIOSSEMIOTICAS, XIII, 2007. Anais do XIII Colóquio do CPS. São Paulo: CPS, 2007. CD-ROM; _. Semiótica e modos de aparência. dObra[s], São Paulo, Estação das Letras e Cores, v. 2, $\mathrm{n}^{\circ} 2$, p. 51-53, fev. 2008.

${ }^{[31]}$ BRACCO, A. Figuratividade do número e simulacros do IBGE na mídia impressa. São Paulo, 2007. Dissertação (Mestrado em Comunicação e Semiótica). Programa de Estudos Pós-Graduados em Comunicação e Semiótica, Pontifícia Universidade Católica de São Paulo.

[32] OLIVEIRA, A. C. de. Interações nas mídias. In: PRIMO, A. et al. Comunicação e interações. Porto Alegre: Sulina, 2008, p. 27-41.

[33] SILVA , S. B. da. A construção do corpo na mídia semanal. São Paulo, 2007. Dissertação (Mestrado em Comunicação e Semiótica). Programa de Estudos Pós-Graduados em Comunicação e Semiótica, Pontifícia Universidade Católica de São Paulo.

${ }^{[34]}$ MESQUITA, L. N. M. A construção de homens e mulheres na revista NOVA: um olhar sociossemiótico. São Paulo, 2003. Dissertação (Mestrado em Comunicação e Semiótica). Programa de Estudos PósGraduados em Comunicação e Semiótica, Pontifícia Universidade Católica de São Paulo.

${ }^{[35]}$ GUIMARÃES, M. P. P. da S. NOVA: 30 anos da mulher de 30. São Paulo, 2006. Dissertação (Mestrado em Comunicação e Semiótica). Programa de Estudos Pós-Graduados em Comunicação e Semiótica, Pontifícia Universidade Católica de São Paulo.

${ }^{[36]}$ MÉDOLA, A. S. L. D. Novela das oito e suas estratégias de textualização: "Terra nostra": a saga ressemantizadora. São Paulo, 2001. Tese (Doutorado em Comunicação e Semiótica). Programa de Estudos Pós-Graduados em Comunicação e Semiótica, Pontifícia Universidade Católica de São Paulo.

${ }^{[37]}$ RODRIGUES, C. A. A. Os gostos de Superbonita e Contemporâneo do GNT na formação de identidades do feminino e do masculino brasileiro. São Paulo, 2008. Dissertação (Mestrado em Comunicação e Semiótica). Programa de Estudos Pós-Graduados em Comunicação e Semiótica, Pontifícia Universidade Católica de São Paulo.

[38] OLIVEIRA, C. M. da B. V. A construção discursiva da mulher brasileira em Retrato Falado, quadro humorístico do programa de televisao Fantástico da Rede Globo. São Paulo, 2009. Tese (Doutorado em Comunicação e Semiótica). Programa de Estudos Pós-Graduados em Comunicação e Semiótica, Pontifícia Universidade Católica de São Paulo. 